\title{
Gene profiling in breast cancer
}

\author{
Inge Peerlink $\cdot$ Kanchan Kaur $\cdot$ Hemant Singhal
}

Received: 16 July 2009

Accepted: 9 September 2009

(C) Indian Association of Surgical

Oncology 2010

Inge Peerlink ${ }^{1}$, Kanchan Kaur ${ }^{1}$, Hemant Singhal $^{1,2}(\bowtie)$

${ }^{1}$ Breast Service, Department of Surgery, Northwick Park Hospital, Harrow

Imperial College, London

e-mail: hemant.singhal@imperial.ac.uk

\begin{abstract}
Breast cancer is a heterogenous disease which shows a great variation in presentation and response to treatment. Currently, the most commonly used prognostic criteria are patient age, tumor size, lymph node status, tumor grade and hormone receptor status. These are however not very accurate. This is partly explained by the fact that they do not demonstrate the inherent genetic variability of breast cancer, which determines the aggressive nature and metastatic potential of the disease. Recent advances in molecular biology have demonstrated that breast cancer is not a single disease. The new diagnostic and prognostic tests based on molecular biology methods have helped identify molecular subtypes of breast cancer that are sensitive to chemotherapy and others that are resistant. This could provide valuable critical information and predict which patients would really benefit from chemo and/or hormonal therapy. Molecular biology will become increasingly important in clinical decision making and as the understanding of molecular processes within cancer cells grow, new targets for therapy will be discovered.
\end{abstract}

Keywords Brest cancer - Cancer cells $\cdot$ Microarray chips

\section{Introduction}

Breast cancer is a heterogenous disease which shows a great variation in presentation and response to treatment. Clinicians have constantly explored indices which would aid in assessing the prognosis and at the same time help in tailoring the most appropriate and effective adjuvant treatment in patients with breast cancer. Currently, the most commonly used prognostic criteria are patient age, tumor size, lymph node status, tumor grade and hormone receptor status (Adjuvant Online, St. Gallen criteria). These are however not very accurate . This is partly explained by the fact that they do not demonstrate the inherent genetic variability of breast cancer which determines the aggressive nature and metastatic potential of the disease. More recently, the development of multigene assays or microarray profiling where fragments of DNA are probed for multiple known genes ${ }^{1}$ has lead to the manufacturing of microarray chips as diagnostic and prognostic probes. These chips can be used to screen large numbers of normal and cancerous tissues for several individual genes at the same time and determine differences in gene expression. These differences, once identified, can lead to a better understanding of carcinogenesis and to the discovery of new drug targets and prognostic and predictive markers, which would identify patients at risk for relapse or patients that are likely to respond to adjuvant therapy.

\section{Treatment decisions in breast cancer}

Breast cancer patients can be treated with surgery alone or with the addition of systemic medical treatment. Prognostic indicators are necessary to determine in which patients the benefits of adjuvant therapy outweigh the risks. Traditionally the choice of treatment is based on clinical, histological and biological parameters. ${ }^{2}$ The Nottingham Prognostic Index (NPI) is based on tumor size, 
tumor grade and lymph node status. The National Institute of Health (USA) and St. Gallen consensus criteria $(\mathrm{EU})^{3}$ use age, tumor size, histological grade, lymphovascular invasion, lymph node status and ER and PR status. Following these criteria up to $90 \%$ of young women with node negative breast cancer would be eligible for adjuvant chemo and/or hormonal therapy. ${ }^{4}$

A large number of these patients would not have developed distant metastasis without adjuvant therapy and have been 'over'-treated and unnecessarily been subjected to potential side-effects of systemic therapy. These prognostic indices do not reliably predict true outcome of disease and result in over treatment of many patients. There is a need for more precise stratification of patient into responders and non-responders to therapeutic agents and into good and bad prognostic outcome. The development of novel molecular tools like PCR and microarrays has lead to a better understanding of the molecular differences between histologically similar tumors that would explain different clinical behavior. A molecular classification of breast cancer based on gene expression profiles was proposed. ${ }^{5,6}$. Four subgroups were identified which were shown to have different prognoses: luminal, basal-like, normal-like and erbB2 positive. Basal-like tumors were mostly ER negative, erbB2 positive tumors were mostly Her2 (human epidermal growth factor receptor)-positive and ER negative and luminal-like tumors were ER positive. These various molecular subclasses have different long-term survival rates and different sensitivities to preoperative chemotherapy.

There is a need for standardized molecular class predictors that can aid in the decision process to determine which patients would benefit the most from systemic treatment.

\section{Multigene predictor tests}

In the last few years a number of multigene prognostic and predictive tests have become available to clinicians. A complete review of all the tests that are currently being developed has been written by Ross et al. ${ }^{7}$ in The Oncologist. Assays can be divided into categories according to the molecular technique that is being used (Table 1).

\section{Immunohistochemistry-based multigene assays}

Immunohistochemistry (IHC) is a technique that uses antibodies against specific cellular markers. A reporter probe is attached to the antibody that is either en enzyme that can catalyze a color producing reaction or a fluorophore that can emit light when excited. Slides are scored using digital image analysis. IHC has been used for the determination of ER and PR status and cell proliferation status (ki67) and has been a very important development in the management of breast cancer.

ProEx ${ }^{\text {TMBr }}$ (TriPath Oncology, Durham, NC) uses five antibodies and an image analysis slide scoring system. The five antibodies used are E2F transcription factor; p21 Ras associated protein, Src kinase protein, secretory leucocyte peptidase inhibitor and proteasome core subunit beta. Over expression of two or more of these genes has been associated with disease relapse in both node negative and node positive patients.

Mammostrat $^{\circledR}$ uses a panel of five antibodies: p53 tumor suppressor protein, N-myc downstream regulated gene 1, carcinoembryonic antigen cell adhesion molecule 5 , solute carrier family 7 cationic amino acid transporter, $\mathrm{y}+$ system member 5 and HpaII tiny fragments locus 9C with routine slide scoring to score ER positive, lymph node negative tumors into low-, moderate- and high-risk of recurrence if treated with tamoxifen alone.

\section{Fluorescent in situ hybridization-based multigene assays}

Fluorescent in situ hybridisation (FISH) uses probes that are fragments of DNA, which are tagged with a fluorophore and bind to those parts of the chromosome with which they show a similarity in sequence. FISH has been used routinely in breast cancer for determination of the copy number of the Her-2 gene which helps in the selection of patients that would benefit from anti-Her-2 targeted therapy.

eXagenBC ${ }^{\mathbf{T M}}$ (eXagen Diagnostics, Inc., Albuquerque, NM) uses fluorescently labelled DNA probes to determine the copy number of three genes for ER positive tumors: cytochrome p450 family 24, programmed cell death 6 interacting protein and baculoviral IAP-repeat containing 5 (survivin) and three genes for ER negative tumors: nuclear receptor subfamily 1 , group $\mathrm{D}$, member $1, \mathrm{SWI} / \mathrm{SNF}$ related, matrix associated, actin dependent regulator of chromatin, subfamily e, member 1 and BIRC5. Prognostic index is determined using an algorithm. Recurrence rates were significantly higher among high risk patients.

The oncotypeDX ${ }^{\mathrm{TM}} \mathrm{RS}$ (recurrence score) assay (www. oncotypedx.com) is a 21-gene assay that determines a 10-year risk for distance recurrence in women with ER positive, lymph node negative tumors and postmenopausal women with node positive, ER positive breast cancer. The likelihood of recurrence or distant metastasis increases continuously with an increase in RS. The score was validated on 668 patients with ER positive, node 
Table 1. Available predictors for breast cancer

\begin{tabular}{|c|c|c|c|c|c|c|}
\hline & & Method & $\begin{array}{l}\text { Sample condi- } \\
\text { tions }\end{array}$ & $\begin{array}{l}\text { No. of } \\
\text { genes }\end{array}$ & Indication & $\begin{array}{l}\text { Guide to specific } \\
\text { therapy }\end{array}$ \\
\hline \multirow[t]{2}{*}{ Classification } & $\begin{array}{l}\text { Sorlie-Perou } \\
\text { Classifier }\end{array}$ & Microarray & Fresh frozen & 427 & $\begin{array}{l}\text { All cases of } \\
\text { invasive } \\
\text { breast cancer }\end{array}$ & no \\
\hline & ARUP bioclassifier & RT-PCR & FFPE & 55 & $\begin{array}{l}\text { ER positive } \\
\text { ER negative } \\
\text { LN negative }\end{array}$ & No \\
\hline Grading & $\begin{array}{l}\text { Sotiriou molecular } \\
\text { grading }\end{array}$ & Microarray & Fresh frozen & 97 & $\begin{array}{l}\text { All cases of } \\
\text { invasive } \\
\text { breast cancer }\end{array}$ & No \\
\hline \multirow[t]{8}{*}{ Prognosis } & ProEx ${ }^{\mathrm{TM}} \mathrm{Br}$ & $\mathrm{IHC}$ & $\begin{array}{l}\text { Formalin } \\
\text { fixed }\end{array}$ & 5 & LN negative & No \\
\hline & Mammostrat $^{\circledR}$ & $\mathrm{IHC}$ & FFPE & 5 & $\begin{array}{l}\text { ER positive } \\
\text { LN negative }\end{array}$ & Yes (tamoxifen) \\
\hline & eXagenBC ${ }^{\mathrm{TM}}$ & FISH & FFPE & 3 & $\begin{array}{l}\text { LN negative } \\
\text { ER positive } \\
\text { ER negative }\end{array}$ & No \\
\hline & MammaPrint $^{\circledR}$ & Microarray & $\begin{array}{l}\text { Fresh frozen; } \\
\text { preserved } \\
\text { mRNA }\end{array}$ & 70 & $\begin{array}{l}\text { ER positive } \\
\text { ER negative }\end{array}$ & No \\
\hline & $\begin{array}{l}\text { Invasiveness gene } \\
\text { signature }\end{array}$ & Microarray & Fresh frozen & 186 & $\begin{array}{l}\text { LN negative } \\
\text { ER positive }\end{array}$ & No \\
\hline & & & & & $\begin{array}{l}\text { ER negative } \\
\text { LN positive } \\
\text { LN negative }\end{array}$ & \\
\hline & oncotypeDX ${ }^{\mathrm{TM}}$ & RT-PCR & FFPE & 21 & ER positive & $\begin{array}{l}\text { Yes (tamoxifen, } \\
\text { adjuvant CMF) }\end{array}$ \\
\hline & & & & & $\begin{array}{l}\text { LN negative } \\
\text { LN positive }\end{array}$ & \\
\hline \multirow{6}{*}{$\begin{array}{l}\text { Prognosis } \\
\text { and response to } \\
\text { therapy }\end{array}$} & Two-gene ratio & RT-PCR & FFPE & 6 & $\begin{array}{l}\text { ER positive } \\
\text { LN negative }\end{array}$ & Yes (tamoxifen) \\
\hline & $\begin{array}{l}\text { Celera metastasis } \\
\text { score }\end{array}$ & RT-PCR & FFPE & 14 & ER positive & Yes (tamoxifen) \\
\hline & & & & & $\begin{array}{l}\text { ER negative } \\
\text { LN positive } \\
\text { LN negative }\end{array}$ & \\
\hline & Rotterdam signature & Microarray & Fresh frozen & 76 & LN negative & $\begin{array}{l}\text { Yes: predictor of TFAC } \\
\text { response } \\
\text { predictor of response } \\
\text { to hormonal } \\
\text { therapy }\end{array}$ \\
\hline & NuvoSelect ${ }^{\mathrm{TM}}$ & Microarray & Fresh frozen & 200 & $\begin{array}{l}\text { ER positive } \\
\text { ER negative } \\
\text { LN positive } \\
\text { LN negative }\end{array}$ & $\begin{array}{l}\text { Yes: predictor of } \\
\text { TFAC response, } \\
\text { Tamoxifen }\end{array}$ \\
\hline & Roche AmpliChip $^{\circledR}$ & Microarray & Fresh frozen & 1 & & Yes: tamoxifen \\
\hline
\end{tabular}

FFPE, Formalin Fixed Paraffin Embedded; LN, Lymph node 
Table 2. the comparison of two clinically relevant and commercially available tests: oncotypeDX ${ }^{\mathrm{TM}}$ and MammaPrint ${ }^{\circledR}$

\begin{tabular}{lll}
\hline & \multicolumn{1}{c}{ OncotypeDX $^{\mathrm{TM}}$} & \multicolumn{1}{c}{ MammaPrint $^{\circledR}$} \\
\hline Starting material & FFPE & Fresh mRNA \\
Number of genes & 21 & 70 \\
Indication & Node negative & Node negative \\
& Node positive & Node positive \\
& ER positive & ER positive \\
& ER negative \\
Patients & Prognostic & $\begin{array}{l}\text { no age discrimination } \\
\text { Type of test }\end{array}$ \\
& Predictive & prognostic \\
Clincal trial & TAILORx & MINDACT \\
Trial design & Who with intermediate RS & Who will have an excellent \\
& will respond to chemotherapy? & outcome without chemotherapy? \\
FDA approval & No & Yes \\
\hline
\end{tabular}

negative breast cancers treated with tamoxifen only. Out of the $51 \%$ of patients with a low RS, $6.8 \%$ recurred at 10 years. Patient with a high RS $(27 \%)$ recurred in $30.5 \%$ of cases at 10 years. In another trial, 651 node negative, ER positive patients of which 227 were treated with tamoxifen alone and 424 with chemotherapy (CMF: cyclophosphamide, methotrexate, 5-fluorouracil) were studied. In this study the assay predicted the benefit from tamoxifen in those with a low or intermediate RS and the benefit from chemotherapy in those with a high RS. The oncotypeDX $\mathrm{X}^{\mathrm{TM}}$ assay has also been studied in ER positive, lymph node positive patients treated with tamoxifen. The findings confirmed the ones obtained in node negative patients.

The National Cancer Institute (US) has sponsored a prospective clinical trial using the oncotypeDX $\mathrm{X}^{\mathrm{TM}}$ to guide the selection of treatment. The Trial Assigning Individualized Options for Treatment (TAILORx) has started recruiting patients in May 2006. The aim of the study is to enrol at least 10,000 women with ER or PR positive, Her-2 negative, lymph node negative breast cancer. The goal is to determine whether patients with intermediate RS benefit from chemotherapy or not. Patients with $\mathrm{RS} \leq 10$ are treated with hormonal therapy alone; patients with a score $\geq 26$ are treated with hormonal therapy and chemotherapy and patients with RS of 11-25 are randomized into either hormonal therapy alone or hormonal therapy and chemotherapy.

Breast cancer two gene expression ratio $(\mathrm{H} / \mathrm{ITM})$ is a six gene assay that is based on the ratio of relative mRNA expression of two genes: the homobox gene B-13 and the interleukin-17B receptor gene. This assay is used to predict recurrence in patients with ER positive, lymph node negative primary breast cancer.
MammaPrint $^{\circledR}$ (van de Vijver $^{8}, 2002 \# 13$ ) is an assay designed for prognostic testing for women under the age of 61 with ER positive or ER negative lymph node negative breast cancer. This assay requires fresh frozen samples or samples stored into RNA-preserving solution. The test was developed in the Netherlands. The 70 genes that were selected for the assay are genes associated with proliferation, invasion, metastasis, stromal integrity and angiogenesis. The test was validated in a multicentre study of European cancer centers. When compared with the St. Gallen criteria, high risk patient determined by the MammaPrint ${ }^{\circledR}$ assay have a higher rate of distant metastasis that the patient classified as high risk by St. Gallen criteria and patient with a low risk as determined by the MammaPrint ${ }^{\circledR}$ assay are more likely to have metastasisfree survival than those classified as low-risk by St. Gallen criteria. The European Organization for Research and Treatment of cancer has sponsored a trial that opened in August 2007: the microarray in node negative disease may avoid chemotherapy (MINDACT) trial, a prospective trial for node negative and node positive disease. All patients are assessed by the standard prognostic index adjuvant online and by the 70 gene MammaPrint ${ }^{\circledR}$ assay. If patients are high risk as predicted by both indices, they receive chemotherapy and hormonal therapy if ER positive. If the patients are considered low risk by both assays, no chemotherapy is given and the patients receive hormonal therapy only if ER positive. If there is a discordance between both indices, patients are randomized to receive treatment based on either the traditional clinicopathological or the genomic predictive test.

Other assays that use microarray are the Rotterdam signature that uses 76 genes, the Invasiveness Gene Signature, that uses 186 genes, NuvoSelect $^{\mathrm{T}}{ }^{\mathrm{M}}$, that uses 30 genes and cytochrome p450 CYP2D6 genotyping, which is an assay that determines response to tamoxifen treat- 
ment by determining the levels of CYP2D6, a liver enzyme that converts tamoxifen to its biological active form.

\section{Discussion}

Recent advances in molecular biology have demonstrated that breast cancer is not a single disease. Histologically identical tumors may show a completely different clinical course. Traditional classification systems and prognostic indices do not provide the sufficient information that is necessary to predict which patients will have a worse outcome and which patients would benefit from adjuvant therapy. This results in over-treatment of large numbers of patient that are unnecessarily exposed to the harmful side-effects of adjuvant treatment. The new diagnostic and prognostic tests based on molecular biology methods have helped identify molecular subtypes of breast cancer that are sensitive to chemotherapy and others that are resistant. This could provide valuable critical information and predict which patients would really benefit from chemo and/or hormonal therapy.

Further validation is necessary to ascertain standardization of methods in different laboratories and more trials are needed to confirm published results. However molecular biology will become increasingly important in clinical decision making and as the understanding of molecular processes within cancer cells grow, new targets for therapy will be discovered.

\section{References}

1. Schena M, Shalon D, Davis RW, Brown PO. Science. 1995;270:467470

2. Eden P, Ritz C, Rose C, Ferno M, Peterson C. Eur J Cancer. 2004;40: 1837-1841.

3. Colomer R, Vinas G, Beltran M, Izquierdo A, Lluch A, LlombartCussac A, Alba E, Munarriz B and Martin M. J Clin Oncol. 2004;22: 961-962

4. van't Veer LJ, Dai H, van de Vijver MJ, et al. Nature. 2002;415:530-506.
5. Perou CM, Sorlie T, Eisen $\mathrm{MB}$, et al. Nature. 2000;406:747-752.

6. Rouzier R., Perou CM, Symmans, WF, et al. Clin Cancer Res. 2005;11:5678-5685.

7. Ross JS, Hatzis C, Symmans WF, Pusztai L, Hortobagyi GN. Oncologist. 2008;13:477-493.

8. van de Vijver MJ, He YD, van't Veer LJ, et al. $N$ Engl J Med. 2002;347:1999-2009.

9. Mullis K, Faloona F, Scharf S, Saiki R, Horn G, Erlich H. Cold Spring
Harb Symp Quant Biol. 1986;51(1): 263-273.

10. Nirenberg M. Trends Biochem Sci. 2004;29:46-54.

11. Paik S. Oncologist 2007;12:631635.

12. Sanger F, Nicklen $\mathrm{S}$ and Coulson AR. Proc Natl Acad Sci USA. 1977;74:5463-5467.

13. Wittner BS, Sgroi D C, Ryan P D, et al. Clin. Cancer Res. 2008;14:29882893. 